\title{
Standardised mortality rates in females and males with COPD and asthma
}

\author{
T. Ringbaek*, N. Seersholm ${ }^{\#}$ and K. Viskum ${ }^{\#}$
}

ABSTRACT: Mortality studies of males and females with chronic obstructive pulmonary disease (COPD) and asthma have suggested that females have a poorer prognosis than males, but the results are either not unanimous or based on poorly characterised patients. The current study analysed the mortality of 279 asthma patients and 869 COPD patients, who were seeking pension due to disability, and compared mortality rates with expected rates derived from the general population.

The mean follow-up period was 13.3 yrs (range 2.5-22.4 yrs) during which time 96 (34.4\%) and $671(77.2 \%)$ deaths were identified among asthma and COPD patients, respectively. The average age at study entry was $\mathbf{4 6 . 8}$ and $\mathbf{5 6 . 6} \mathrm{yrs}$, and the average forced expiratory volume in one second (FEV1) was 68.8 and $44.1 \%$ predicted in the two diagnostic groups. After adjustment for predictors of survival (age, FEV 1 \% predicted, chronic bronchitis, body mass index, smoking status, oral prednisolone, ischaemic heart disease, and cor pulmonale), the relative risk of death was 1.21 (95\% confidence interval: $0.77-1.89)$ and $0.98(0.83-1.16)$ in females compared with males, in asthma and COPD patients, respectively.

The standardised mortality rate (SMR) for males was 1.54 (1.10-2.09) and 2.7 (2.5-3.0), and for females 1.91 (1.44-2.49) and 4.8 (4.2-5.4), in asthma and COPD patients, respectively. Direct comparison of the SMR of males and females showed that females had higher mortality than males, with a rate ratio of $1.24(0.82-1.84)$ and $1.8(1.5-2.0)$, in asthma and COPD patients, respectively. Poisson regression analysis with control for the confounders did not change this result.

Females and males with the same level of obstructive lung disease appear to have the same level of mortality. However, using standardised mortality rates, females have a higher mortality than males, suggesting that the protective effect of being female is lost in chronic obstructive pulmonary disease patients.

KEYWORDS: Chronic obstructive pulmonary disease, lung function, sex, survival, pension

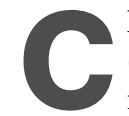
hronic obstructive pulmonary disease (COPD) is one of the leading causes of morbidity and mortality and, while the mortality rate is stable among males, it is increasing among females [1-4]. Several studies have shown that mortality is increased in patients with asthma and COPD, with increasing excess mortality related to low forced expiratory volume in one second (FEV1) [5-12]. Studying asthma patients, MARKOWE et al. [7] and SUNYER et al. [11] found higher excess mortality in females compared with males, although other studies reported no sex difference $[5,8,9]$. Some of these studies are dated, and patients were treated according to guidelines created before the introduction of inhaled corticosteroids.

The existence of sex-related survival differences in COPD has also been considered [11]. In a study of COPD patients who visited emergency rooms,
SUNYER et al. [11] showed that excess mortality from all causes and respiratory disease was higher in females compared with males. However, they have not reported data on lung function, smoking habits, medication, pulmonary symptoms or comorbidity. In this prospective study of patients with asthma and COPD, sexrelated differences in mortality rates and excess of mortality were studied.

\section{METHODS}

From 1977-1997, 2,200 patients with pulmonary symptoms were referred to two specialists in pulmonary medicine for medical evaluation of disability. Before the patients, always as outpatients and during stable medical condition, were evaluated, most had been in contact with a specialist practice or a hospital. Before the evaluation by the pulmonary specialists, most of the patients had a reversibility test with inhaled
AFFILIATIONS

${ }^{\star}$ Dept of Pulmonary Medicine, Hvidovre University Hospital, and \#Dept of Pulmonary Medicine, Gentofte University Hospital, Copenhagen, Denmark.

CORRESPONDENCE

T. Ringbaek

Krogebakke 2 B

DK-3140 Aalsgaarde

Denmark

Fax: 4536323716

E-mail: Ringbaek@dadlnet.dk

Received:

August 252004

Accepted after revision:

December 102004 
$\beta_{2}$-agonists and some with oral corticosteroids. If the result of such a test was ambiguous or had not been performed, a reversibility test using $2 \mathrm{mg}$ of terbutaline from an inhalator was administered (49.7\% of the patients). COPD was defined as $\mathrm{FEV} 1<80 \%$ of predicted value, a FEV1/forced vital capacity (FVC) ratio $<70 \%$, and exclusion of other obstructive airway diseases, such as asthma and bronchiectasis. The two pulmonary specialists made the diagnosis after an evaluation, including a file of previous examinations as an outpatient or during hospitalisation, a lung function test, reversibility tests and, frequently, additional tests (total lung capacity in $48.1 \%$ and diffusion capacity in $1.9 \%$ ). In this study, the asthma diagnosis was used if the patient had any asthmatic component, including an absolute increase in FEV1 $>250 \mathrm{~mL}$ after $\beta_{2^{-}}$ reversibility test. Chronic bronchitis was defined as phlegm $\geqslant 3$ months in 2 consecutive yrs. All patients were asked the same questions and had FEV1 and FVC measured with a spirometer (Vitalograph, Ennis, Ireland) [12]. The study comprised 1,148 subjects. COPD was diagnosed in 869 cases and asthma in 279 cases. Patients with comorbidity from actual cancer, previous pulmonary resection, ciliary dyskinesia, bronchiectasis, cystic fibrosis, $\alpha_{1}$-antitrypsin deficiency, simple chronic bronchitis with normal lung function, actual or previous pulmonary tuberculosis or pneumothorax, and 17 patients with both COPD and asthma were excluded.

The number of pack-yrs of tobacco was calculated (one cigarette $=1 \mathrm{~g}$, one cheroot $=3.5 \mathrm{~g}$, one cigar $=5 \mathrm{~g}$, pipe tobacco: actual number of grams). As ischaemic heart disease is a frequent contributor of pulmonary symptoms in tobacco smokers, this disease was also reported. A diagnosis of ischaemic heart disease was based on the previous files, and from the history and physical examination obtained by the pulmonary specialist, a diagnosis of ischaemic heart disease was made.

The National Health Services Central Register ascertained vital status until September 1, 2003. The mean follow-up period was

\section{TABLE 1 Characteristics of patients applying for benefits due to disability according to respiratory disease and sex, and the number of deaths}

\begin{tabular}{|c|c|c|c|c|c|}
\hline \multirow[t]{2}{*}{ Groups } & \multirow[t]{2}{*}{ Subjects $\mathbf{n}$} & \multicolumn{2}{|c|}{ Asthma } & \multicolumn{2}{|c|}{ COPD } \\
\hline & & Males & Females & Males & Females \\
\hline Subjects $n$ & 1148 & 104 & 175 & 494 & 375 \\
\hline Age yrs & 1148 & $46.4 \pm 19.0$ & $47.1 \pm 11.1$ & $57.7 \pm 8.5$ & $55.0 \pm 6.9$ \\
\hline FEV $1 \%$ predicted & 1145 & $64.4 \pm 20.4$ & $71.4 \pm 21.8$ & $43.4 \pm 17.4$ & $45.2 \pm 15.8$ \\
\hline GOLD ${ }^{\#}$ & 1148 & & & & \\
\hline Stage II moderate \% & & & & 33.4 & 38.7 \\
\hline Stage III severe \% & & & & 39.7 & 41.6 \\
\hline Stage IV very severe \% & & & & 26.9 & 19.7 \\
\hline FVC \% predicted & 1142 & $79.0 \pm 16.6$ & $82.4 \pm 18.0$ & $63.2 \pm 16.1$ & $64.9 \pm 16.5$ \\
\hline BMI $\mathbf{k g} \cdot \mathrm{m}^{-2}$ & 1130 & $25.6 \pm 4.7$ & $25.9 \pm 5.4$ & $25.8 \pm 5.5$ & $23.7 \pm 5.6$ \\
\hline Smoking status \% & 1117 & & & & \\
\hline Never & & 20.0 & 32.7 & 2.3 & 4.1 \\
\hline Ex & & 33.0 & 27.3 & 23.1 & 25.3 \\
\hline $1-15$ cigarettes & & 25.0 & 22.4 & 18.6 & 29.2 \\
\hline$>15$ cigarettes & & 22.0 & 17.6 & 56.1 & 41.4 \\
\hline Pack-yrs median (min-max) & 1102 & $18.0(0-66)$ & $6(0-49)$ & $36(0-99)$ & $30(0-75)$ \\
\hline Chronic bronchitis \% & 1148 & 17.3 & 17.7 & 83.2 & 85.3 \\
\hline Dyspnoea on effort \% & 1148 & 79.8 & 83.4 & 96.8 & 97.9 \\
\hline Attack of dyspnoea \% & 1148 & 76.0 & 79.4 & 12.8 & 20 \\
\hline Dyspnoea at rest \% & 1148 & 7.7 & 6.3 & 3.8 & 7.5 \\
\hline Nocturnal dyspnoea \% & 1148 & 41.3 & 51.4 & 12.3 & 16.5 \\
\hline Prednisolone p.o. \% & 1146 & 18.3 & 16.6 & 6.7 & 5.3 \\
\hline Inhaled steroid \% & 1146 & 53.8 & 64.6 & 14.6 & 22.4 \\
\hline$\beta_{2}$-agonist \% & 1146 & 84.6 & 88.0 & 52.8 & 62.1 \\
\hline Inhaled ipratropium \% & 1146 & 7.7 & 7.4 & 7.5 & 8.3 \\
\hline Theophylline \% & 1146 & 32.7 & 46.3 & 28.5 & 33.1 \\
\hline Ischaemic heart disease \% & 1148 & 1.9 & 1.1 & 10.7 & 3.5 \\
\hline Cor pulmonale \% & 1148 & 1 & 0.6 & 4.9 & 4.3 \\
\hline Period of examination (I/II/III) & 1148 & $30.8 / 40.4 / 26.0$ & $36.6 / 34.9 / 28.6$ & $42.9 / 34.8 / 22.3$ & $39.2 / 34.7 / 26.1$ \\
\hline Deaths n (\%) & 1148 & $41(39.4)$ & $55(31.4)$ & $391(79.1)$ & $280(74.7)$ \\
\hline
\end{tabular}

Data are presented as mean \pm SD, unless otherwise stated. COPD: chronic obstructive pulmonary disease; FEV1: forced expiratory volume in one second; GOLD: Global Initiative for Chronic Obstructive Lung Disease; FVC: forced vital capacity; BMI: body mass index; Period I: 1977-1983; Period II: 1984-1989; Period III: 1990-1996. \#. classification of severity of COPD according to GOLD [13]. 
13.1 yrs (range 2.5-22.4 yrs), during which time 767 (66.8\%) deaths were identified among the 1,148 patients. Eight patients had emigrated, and survival until emigration was included.

\section{Statistics}

Cox proportional hazards regression was used to determine whether sex was associated with increased mortality from all causes. The hazard ratios (relative risks (RR)) were calculated for the following covariates, which were defined a priori: age, FEV1 \% predicted $(<40,40-59,60-79$ and $\geqslant 80)$, body mass index $\left(<20,20-24.9,25-29.9\right.$ and $\left.\geqslant 30 \mathrm{~kg} \cdot \mathrm{m}^{-2}\right)$, pack-yrs of smoking $(0,1-19,20-39$ and $\geqslant 40)$, smoked tobacco at evaluation $\left(0,1-14\right.$ and $\left.\geqslant 15 \mathrm{~g} \cdot \mathrm{day}^{-1}\right)$, treatment with prednisolone (yes/no), treatment with inhaled corticosteroids (yes/ no) comorbidity from ischaemic heart disease (yes/no), chronic bronchitis (yes/no), and, finally, cor pulmonale (yes/ no). The hazard ratios were adjusted for those covariates, which were related to death. Adjusting for period of entrance did not change the results.

Continuous variables were transformed into the standardised categories as listed above if linearity was not present. Assumption of linearity was assessed by categorising the variable into multiple dichotomous variables of equal units on the variable's scale. The estimated coefficients of each dichotomous variable were compared. The period of followup for survival calculation was taken from the date of the first examination, to the date of death, emigration, or September 1, 2003, whichever came first. Expected survival rate was calculated from age, calendar time, and sex-specific mortality tables of the Copenhagen (Denmark) area published by the Danish Statistical Bureau. The rate ratios for mortality were calculated as the ratio of the observed number of deaths per person year of follow-up to the expected death rate. These rate ratios are referred to as RR. Chi-squared tests were used for univariate analysis and Poisson regression analysis used for multivariate analysis of mortality rates.

Analyses were employed for patients with asthma and COPD, separately. A two-sided p-value of $<0.05$ was considered significant.

\section{RESULTS}

Characteristics of the study groups are shown in table 1 .

\section{Asthma patients}

During the follow-up time, 96 of the 279 patients with asthma died. The median survival time was 17.7 yrs for patients with

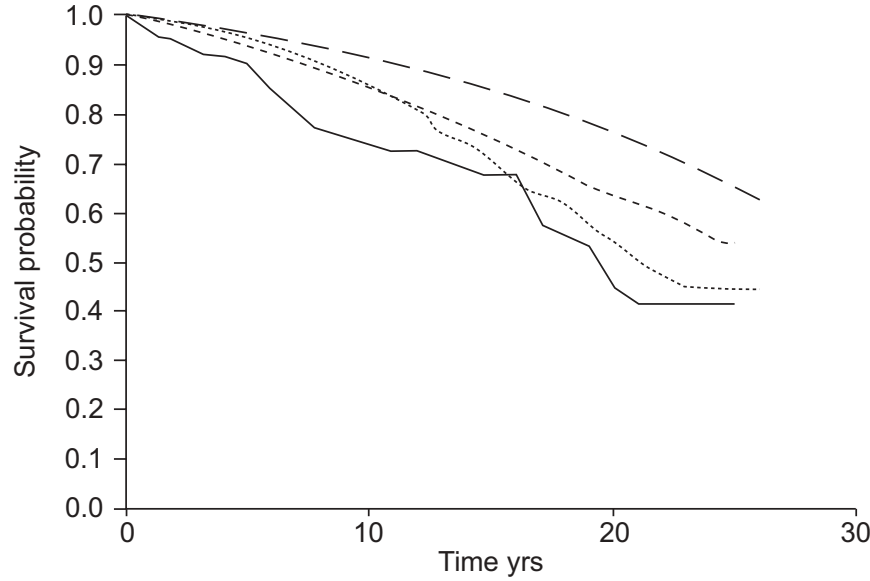

FIGURE 1. Observed and expected life table plot of males and females with asthma. - - -: females expected; ..... females observed; - - -: males expected; _ : males observed.

asthma, with a tendency towards a decreased risk of mortality for females (RR: 0.77 (0.51-1.15); fig. 1). Adjustment for predictors of survival (covariables listed in statistics) increased the RR of mortality for females to 1.21 (0.77-1.89).

Compared to an age-matched control group, the mortality rates were increased significantly by a factor of 1.54 (1.10-2.09) in males and 1.91 (1.44-2.49) in females with asthma (table 2). This sex-related difference in excess of all cause mortality was not significant, with risk ratio of $1.24(0.82-1.84 ; \mathrm{p}=0.33)$.

\section{COPD patients}

During the follow-up time 671 of the 869 patients with COPD died. The median survival time for patients with COPD was $8.5 \mathrm{yrs}$, with a significantly lower risk of mortality in females compared with males (RR: 0.75 (0.64-0.88); fig. 2). After adjustment for predictors of survival (listed in statistics), the RR of death was $0.98(0.83-1.16)$ in females compared with males (table 3).

Compared to an age-matched control group, the mortality rates were increased significantly by a factor of $2.7(2.5-3.0)$ in males and 4.8 (4.2-5.4) in females with COPD (table 2). This sex-related difference in excess of all-cause mortality was significant with a risk ratio of $1.8(1.5-2.0)$.

TABLE 2 Excess of mortality in patients with asthma and chronic obstructive pulmonary disease (COPD) separately for each sex

\begin{tabular}{|c|c|c|c|c|c|c|}
\hline & \multicolumn{3}{|c|}{ Asthma } & \multicolumn{3}{|c|}{ COPD } \\
\hline & Male & Female & Both & Male & Female & Both \\
\hline Patients $\mathbf{n}$ & 104 & 175 & 279 & 494 & 375 & 869 \\
\hline O/E n & $41 / 26.6$ & $55 / 55.4$ & $96 / 55.4$ & $391 / 143.9$ & 280/58.6 & $671 / 202.4$ \\
\hline Excess of mortality $\mathrm{O} / \mathrm{E}(95 \% \mathrm{Cl})$ & $1.5(1.1-2.1)$ & $1.9(1.4-2.5)$ & $1.7(1.4-2.1)$ & $2.7(2.5-3.0)$ & $4.8(4.2-5.4)$ & $3.3(3.1-3.6)$ \\
\hline
\end{tabular}

Data are calculated from the observed number of deaths $(\mathrm{O})$ and the expected number of deaths from the regional population $(\mathrm{E})$ after adjusting for age and sex. $\mathrm{Cl}$ confidence interval. 


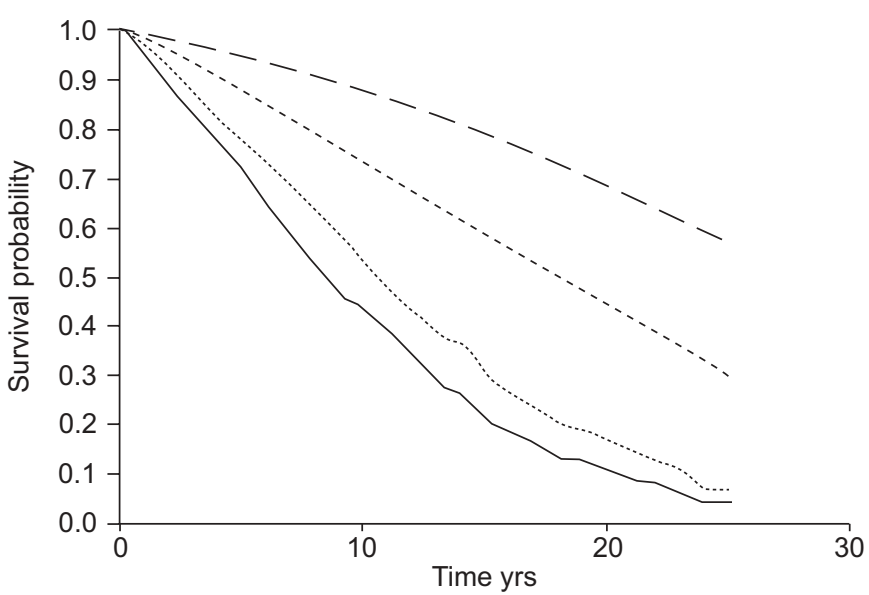

FIGURE 2. Observed and expected life table plots of males and females with chronic obstructive pulmonary disease. - - - females expected; ...... females observed; - - -: males expected; —_: males observed.

\section{DISCUSSION}

The major finding in this study is that although the survival of males and females was similar, comparison of standardised mortality rate (SMR), which adjusted for expected survival, showed that females had higher SMR than males, suggesting that females with COPD lose more years of their lives than males. The females had the same degree of disease severity (lung function and treatment with oral glucocorticoids) and were even smoking less. These results are in accordance with the studies of SUNYER et al. [11], MARKOWE et al. [7] and LANGE et al. [14] (table 4). SUNYER et al. [11] found ratios between females and males of 1.21 and 1.15, respectively, regarding the risk of excess mortality in COPD and asthma patients [11]. Due to a high number of deaths in their study, these sex-related risks of excess mortality were statistically significant [11]. In the current study, the mortality rates were similar for females $\left(\sim 45 / 1,000\right.$ patient $\left.\cdot \mathrm{yr}^{-1}\right)$ and slightly lower for males compared with the Spanish study (63 versus 90/1,000 patient $\cdot \mathrm{yr}^{-1}$ ) [11]. They had included a lower number of females with COPD, but a closer comparison is not possible, because they had not reported data on lung function, medication, smoking habits, pulmonary symptoms or comorbidity. Data from the Copenhagen City Heart Study, a prospective population study, showed that subjects with FEV $1<40 \%$ had an increased risk of mortality compared with a matched control group with normal

\begin{tabular}{|c|c|c|}
\hline TABLE 3 & \multicolumn{2}{|c|}{$\begin{array}{l}\text { Risk factors presented as hazard ratios among } \\
\text { patients with chronic obstructive pulmonary } \\
\text { disease for any cause of deaths, using Cox } \\
\text { regression analysis }\end{array}$} \\
\hline Sex male $=1$ & & $0.95(0.80-1.13)$ \\
\hline \multicolumn{3}{|l|}{$\mathrm{FEV}_{1} \%$} \\
\hline$<40$ & & 1 \\
\hline $40-59$ & & $0.63(0.52-0.75)$ \\
\hline $60-79$ & & $0.36(0.29-0.47)$ \\
\hline Age $1 \mathrm{yr}$ & & $1.04(1.03-1.05)$ \\
\hline \multicolumn{3}{|l|}{$B M I \mathbf{k g} \cdot \mathrm{m}^{-2}$} \\
\hline$<20$ & & 1 \\
\hline $20-24.9$ & & $0.73(0.58-0.91)$ \\
\hline $25-29.9$ & & $0.65(0.51-0.82)$ \\
\hline$\geqslant 30$ & & $0.62(0.47-0.81)$ \\
\hline \multicolumn{3}{|c|}{ Pack-yrs of smoking } \\
\hline 0 & & 1 \\
\hline $1-19$ & & $2.43(1.23-4.80)$ \\
\hline 20-39 & & $2.74(1.40-5.38)$ \\
\hline$\geqslant 40$ & & $3.55(1.77-7.10)$ \\
\hline \multicolumn{2}{|c|}{ Oral prednisolone } & $1.68(1.18-2.39)$ \\
\hline \multicolumn{2}{|c|}{ Ischaemic heart disease } & $1.85(1.38-2.50)$ \\
\hline \multicolumn{2}{|c|}{ Cor pulmonale } & $1.77(1.25-2.49)$ \\
\hline
\end{tabular}

Data are presented as relative risks (95\% confidence interval). Only statistically significant hazard ratios are shown. FEV1: forced expiratory volume in one second; BMl: body mass index.

FEV1, with a RR of 5.0 for females and 2.7 for males [14]. Compared with a matched control group, MARKOWE et al. [7] found that asthma patients from general practitioners had an increased risk of mortality (RR of 2.19 in females and 1.39 in males) [7]. A population-based study of patients with selfreported asthma and 161 deaths found a tendency towards higher excess of mortality in females compared with males $(\mathrm{RR}=1.7$ versus 1.5$)$ [8]. However, two older studies of asthma patients have reported no sex-related difference in excess of mortality (table 4), and they have not presented data on smoking history $[5,9]$. In the current study, only $32.7 \%$ of the females were never-smokers, and this is expected to be less than in the old asthma studies [5,9]. This may explain why they did not find a higher excess of mortality in females compared with males. Using data from Danish population studies, PRESCOTT et al. $[15,16]$ showed that, among smokers,

TABLE 4 Studies examining the excess of mortality in patients with asthma, for each sex separately

\begin{tabular}{|c|c|c|c|c|c|c|}
\hline LANGE et al. [8] & Population study & $1976-1978$ & 315 & 161 & $1.7 / 1.5$ & $1.13(F=M)$ \\
\hline MARKowe et al. [7] & GP-national survey & 1970-1976 & 2547 & 189 & $2.19 / 1.39$ & $1.58(F>M)^{*}$ \\
\hline SUNYER et al. [11] & Emergency department & 1985-1989 & 4555 & 643 & $1.39 / 1.21$ & $1.15(F>M)^{*}$ \\
\hline
\end{tabular}

Data are calculated from the observed number of deaths $(\mathrm{O})$ and the expected number of deaths $(E)$. GP: general practitioner; F: females; M: males. ${ }^{*}: \mathrm{p}<0.05$. 
females had an increased loss of lung function and risk of dying from respiratory and vascular diseases compared with males. In the current study, the excess mortality in females was independent of smoking status at evaluation (data not shown).

It should be considered that the patients were only evaluated at the time of the referral, and they might later have changed smoking status. However, the current authors believe that this number is about the same for males and females. According to the Lung Health Study, which evaluated patients for 5 yrs, smoking cessation intervention leads to sustained smoking cessation in $18.3 \%$ of males and $15.7 \%$ of females [17]. Misclassification of COPD and asthma is a known problem, especially among the elderly. A separation of asthma from COPD is based on several clinical parameters. In the current study, data on smoking history, symptoms (attack of dyspnoea, nocturnal dyspnoea and chronic bronchitis), and use of inhaled steroid support a correct separation in most cases. When the reduced life expectancy was seen in both COPD and asthma patients, any misclassification would only increase the risk for one subgroup at the expense of the other subgroup.

It cannot be excluded that seeking pension depended on sex. According to data from The Board of Danish Statistics, the percentage of unemployment in males was constantly $\sim 2 \%$ higher than for females in the studied area, and the number of males who received a pension in this area was constantly some $15 \%$ higher than for females. This indicates that more males than females were seeking a pension. However, the current patients were well characterised, and females seem not to have more severe disease compared with males.

The patients in the current study were characterised by having pulmonary symptoms, and all chronic obstructive pulmonary disease patients had moderate to very severe disease. Therefore, the present findings do not represent all asthma and chronic obstructive pulmonary disease patients. Further studies are needed in patients with mild chronic obstructive pulmonary disease. Data from the current study support previous findings that females with obstructive lung disease, especially chronic obstructive pulmonary disease, had higher excess mortality compared with males.

\section{REFERENCES}

1 Mannino DM, Brown C, Giovino GA. Obstructive lung disease deaths in the United States from 1979 through 1993. An analysis using multiple-cause mortality data. Am J Respir Crit Care Med 1997; 156: 814-818.

2 Higgins MW. Chronic airways disease in the United States. Trends and determinants. Chest 1989; 96: Suppl. 3, 328S-334S.

3 Peto R, Lopez AD, Boreham J, Thun M, Heath C Jr. Mortality from tobacco in developed countries: indirect estimation from national vital statistics. Lancet 1992; 339: 1268-1278.

4 Feenstra TL, van Genugten ML, Hoogenveen RT, Wouters EF, Rutten-van Molken MP. The impact of aging and smoking on the future burden of chronic obstructive pulmonary disease: a model analysis in the Netherlands. Am J Respir Crit Care Med 2001; 164: 590-596.

5 Toren K, Lindholm NB. Do patients with severe asthma run an increased risk from ischemic heart disease? Int J Epidemiol 1996; 25: 617-620.

6 Robinette CD, Fraumeni JF Jr. Asthma and subsequent mortality in World War II veterans. J Chronic Dis 1978; 31: 619-624.

7 Markowe HLJ, Bulpitt CJ, Shipley MJ, Rose G, Crombie DL, Fleming DM. Prognosis in adult asthma: a national study. BMJ 1987; 295: 949-952.

8 Lange P, Ulrik CS, Vestbo J. Mortality in adults with selfreported asthma. Copenhagen City Heart Study Group. Lancet 1996; 347: 1285-1289.

9 Alderson M, Loy RM. Mortality from respiratory disease at follow-up of patients with asthma. Br J Dis Chest 1977; 71: 198-202.

10 Connolly CK, Alcock SM, Prescott RJ. Mortality in asthmatics over 15 yrs: a dynamic cohort study from 1983-1998. Eur Respir J 2002; 19: 593-598.

11 Sunyer J, Anto JM, Mcfarlane D, et al. Sex differences in mortality of people who visited emergency rooms for asthma and chronic obstructive pulmonary disease. Am J Respir Crit Care Med 1998; 158: 851-856.

12 Ringbaek TJ, Viskum K. Is there any association between inhaled ipratropium and mortality in patients with COPD and asthma? Respir Med 2003; 97: 264-272.

13 Global initiative for Chronic Obstructive Lung Disease (GOLD). Publication no. 2701. Bethesda, National Institutes for Health, 2001 (2003 update).

14 Lange P, Nyboe J, Appleyard M, Jensen G, Schnohr P. Relation of ventilatory impairment and of chronic mucus hypersecretion to mortality from obstructive lung disease and from all causes. Thorax 1990; 45: 579-585.

15 Prescott E, Bjerg AM, Andersen PK, Lange P, Vestbo J. Gender difference in smoking effects on lung function and risk of hospitalization for COPD: results from a Danish longitudinal population study. Eur Respir J 1997; 10: 822-827.

16 Prescott E, Osler M, Andersen PK, et al. Mortality in women and men in relation to smoking. Int $J$ Epidemiol 1998; 27: 27-32.

17 Connett JE, Murray RP, Buist AS, Bailey WC, Lindgren PG, Owens GR, Lung Health Study Research Group. Changes in smoking status affect women more than men: results of the Lung Health Study. Am J Epidemiol 2003; 153: 973-979. 